Irriga, Botucatu, v. 7, n. 2, 2002

\title{
DIAGNÓSTICO FÍSICO CONSERVACIONISTA DE 10 MICROBACIAS DO RIO CAPIVARA - BOTUCATU (SP), VISANDO O USO RACIONAL DO SOLO
}

\author{
Armindo Alves de Araújo Júnior \\ Sérgio Campos \\ Zacarias Xavier de Barros \\ Lincoln Gehring Cardoso \\ Departamento de Engenharia Rural, Faculdade de Ciências Agronômicas, Universidade Estadual \\ Paulista, CP 237, CEP 18603-970, Botucatu - SP, E-mail: seca@fca.unesp.br
}

\section{RESUMO}

A região onde está inserida a área de estudo, tem sofrido explorações predatórias e má utilização do solo. Áreas antes ocupadas por cerrados, campos sujo e limpo foram substituídas pelos reflorestamentos com eucalipto, devido aos incentivos fiscais e a instalação de companhias reflorestadoras na região, pelo baixo valor das terras e baixa fertilidade do solo; mas com um grande potencial para o desenvolvimento de essências florestais. O presente trabalho visou a elaboração do Diagnóstico Físico Conservacionista da bacia do rio Capivara - Botucatu (SP), baseada no parâmetro ambiental "Coeficiente de Rugosidade", tendo-se por unidade de estudo 10 microbacias. Os resultados obtidos com a metodologia utilizada, no estudo da bacia do rio Capivara - Botucatu (SP), para o diagnóstico físico conservacionista permitiram mostrar que o grau de deterioração físico ambiental para a bacia foi 44,34\%, muito acima do limite de $10 \%$ aceitável. $\mathrm{O}$ alto valor do grau de deterioração, provavelmente, foi devido ao mau uso da terra que vem provocando erosões, assoreamentos de reservatórios e cursos d'águas. O parâmetro ambiental médio "coeficiente de rugosidade" para as dez microbacias do rio Capivara, permitiu classificá-las para utilização com agricultura e urbanização, pecuária e reflorestamento; ou seja, indicou que a vocação principal desta é para uso com pecuária (Classe B); as classes de declive de 0 a 12\% (Classe III) e de 12 a $20 \%$ (Classe IV), respectivamente, predominaram em $62,95 \%$ e $27,00 \%$ da área total das microbacias estudadas, ocorrendo em na sua maior parte nas unidades de solo LVA (46,56\%) e RQ (19,86\%). A predominância de florestas, capoeiras e pastagens nas microbacias, provavelmente é reflexo da predominância de solos de baixa fertilidade. - As imagens do Sensor TM do LANDSAT 5, permitiram o mapeamento do uso da terra da bacia de maneira rápida, que segundo o índice Kappa foi de boa qualidade $(0,45)$, além de fornecer um banco de dados para futuros planejamentos nessa área. O SIG IDRISI permitiu constatar através de seus diferentes módulos para georreferenciamento, classificação digital do uso da terra e modelo matemático, as áreas de uso da terra com rapidez. Os parâmetros, coeficientes de forma e circularidade mostraram que as microbacias apresentam baixo perigo de enchentes devido ao seu formato, bem como, o coeficiente de rugosidade permitiu classificar as microbacias 1, 2, 3, 4 e 8 com vocação para agricultura; as 6 e 7 para pecuária; a 5 para pecuária e reflorestamento e as 9 e 10 para floresta e reflorestamento.

UNITERMOS: Coeficiente de Rugosidade, diagnóstico físico consevacionista, microbacia e unidades de solo. 


\section{ARAÚJO JÚNIOR, A.A., CAMPOS, S., BARROS, Z.X., CARDOSO, L.G. PHYSICAL CONSERVATION DIAGNOSIS OF TEN WATERSHEDS OF CAPIVARA RIVER AIMING A RATIONAL SOIL OCCUPATION.}

\section{SUMMARY}

The region where the study was focused has been under predatory exploitation and bad land usage. Areas that had been initially scrublands and clean and dirty fields are now being replaced by eucalyptus reforestation as a result of both tax incentives and low price lands (in that specific usage) but with a great potential for forest essence development. This study aimed to elaborate the physical conservation diagnosis of ten watersheds of Capivara River for rational soil occupation, based on the coefficient of roughness. The results and the methodology applied in the study showed that the level of environmental physical deterioration was $44.34 \%$ and it was much higher than the $10 \%$ acceptable limit. The high deterioration level was probably due to bad land usage which has been causing erosion, silting of water reservoir and creek sedimentation. The average environmental parameter coefficient of roughness for the watersheds of Capivara River allowed their classification for agricultural, cattle-raising and reforestation usage, i.e., mainly for cattle-raising usage ( B Class). The watershed largest part (62.95\%) belongs to 0 to $12 \%$ slope class, in LVA $(46.56 \%)$ and RQ $(19.86 \%)$ soil units. The forest, savanna and grazing land predominance is probably a consequence of low fertility soil presence in the watershed (RQ and LVA). The 5 LANDSAT TM sensor images allowed land usage mapping quickly as well as provided database for future planning. The SIG-IDRISI allowed to verify through its different modules for georeference, digital classification of soil usage and mathematical model, the areas of land using quickly. The parameters, the form and circularity indexes showed that the watersheds are at risk of flood due to their format. The coefficient of roughness classified the 1, 2, 3, 4 and 8 watersheds for agricultural purposes; 6 and 7 for cattleraising; 5 for cattle-raising and reforestation and 9 and 10 for forest and reforestation.

KEY-WORDS: Ruggdness nunber, physical conservation diagnosis, watershed and soil units

\section{INTRODUÇÃO}

A melhoria e conservação do meio ambiente é, atualmente, uma preocupação mundial. Porém, são raros os trabalhos desenvolvidos no Brasil que visam a avaliação do grau de deterioração ambiental.

A deterioração dos recursos naturais, principalmente do solo e água vem crescendo na região de Botucatu com o passar dos anos, devido ao uso da terra sem planejamento e má utilização dos recursos naturais e renováveis.

A microbacia é uma unidade física ideal para estudos e planejamento integrado de recursos naturais e renováveis, por ser uma unidade ecológica com contornos naturais e constituir-se num ecossistema que precisa ser planejado de maneira racional.

O mapeamento de uma microbacia permite estudos e planejamentos de atividades urbanas e rurais, com determinação do uso e ocupação do solo, indicação de áreas mais propícias à exploração agrícola, pecuária ou florestal, previsão de safras e planejamento urbano.

O levantamento do uso da terra é um dos primeiros passos para avaliar os recursos dos solos quanto à sua capacidade produtiva, localização e quantificação, bem como, para evitar-se o uso inadequado e desordenado dos recursos naturais. Essas informações 
atualizadas são essenciais para o manejo eficiente dos recursos agroflorestais.

O diagnóstico físico conservacionista de microbacias é importante e necessário porque permite analisar os conflitos detectados entre o uso atual e a capacidade de uso das terras e visa avaliar os problemas ocasionados pelas enchentes, secas e erosões.

Os solos das microbacias vêm sendo conduzidos sem técnica nenhuma de conservação, ocasionando com isso redução da fertilidade dos nossos solos e em conseqüência, o empobrecimento natural das espécies vegetais e até a extinção da microfauna. Estes solos são altamente sensíveis a erosão, principalmente a laminar que é praticamente imperceptível, provocando nos rios o assoreamentos, podendo manter até sob ameaça de inundação, principalmente as regiões urbanas.

A pesquisa teve como objetivo realizar o diagnóstico físico conservacionista de 10 microbacias ocorrentes no interior da bacia do Rio Capivara - Botucatu (SP), baseando-se no parâmetro ambiental "Coeficiente de Rugosidade", utilizando-se do geoprocessamento no estudo da ocupação do solo das microbacias através do Sistema de Informação Geográfica (SIG) - IDRISI for WINDOWS e de imagens de satélite.

\section{MATERIAL E MÉTODOS}

\subsection{Material}

\subsubsection{Descrição geral da área}

O presente trabalho foi desenvolvido com base na bacia do Rio Capivara, localizada no Município de Botucatu (SP), por ser uma área representativa do município onde a paisagem natural sofreu uma nítida transformação. Essa bacia situa-se geograficamente entre as coordenadas: $48^{\circ} 17$ ' $34^{\prime \prime}$ a $48^{\circ} 26^{\prime} 28^{\prime \prime}$ de longitude W Gr. e $22^{\circ} 43^{\prime} 38^{\prime \prime}$ a $22^{\circ} 57^{\prime} 39^{\prime \prime}$ de latitude $\mathrm{S}$, apresentando uma área territorial de aproximadamente 21912,13 hectares.
O clima predominante do município, classificado segundo o sistema Köppen é do tipo Cfa - clima temperado chuvoso e a direção do vento predominante é a sudeste (SE).

A temperatura média anual, segundo Martins (1989) na região, é de $20,2^{\circ} \mathrm{C}$, sendo as temperaturas médias dos meses mais quentes de $23,2{ }^{\circ} \mathrm{C}$ e de $16,9{ }^{\circ} \mathrm{C}$ nos meses mais frios.

A precipitação média anual está ao redor de $1.447 \mathrm{~mm}$, ocorrendo uma precipitação média no mês mais chuvoso e mais seco, respectivamente, de $223,4 \mathrm{~mm}$ e $37,8 \mathrm{~mm}$.

Segundo Oliveira et al. (1999), os solos ocorrentes na área foram classificados como: Latossolo Vermelho-Amarelos (LVA), Latossolo Vermelhos (LV); Neossolos Quartzarênico Argissólico e Latossólico (RQ) e Neossolos Litólicos(RL).

As unidades Neossolos Quartzarênico Argissólico e Latossólico (RQ), conforme Oliveira et al. (1999), são solos profundos, de textura muito leve, acentuadamente drenados, de cor geralmente vermelho amarelado, com seqüência de horizontes $\mathrm{A}, \mathrm{B}$ e $\mathrm{C}$, originados a partir de arenitos, de fertilidade baixa, ácidos e muito susceptíveis à erosão.

O conteúdo de argila é baixo, sendo menor de $15 \%$, variando de 7,8 a $15 \%$ nos horizontes $\mathrm{A}$ e $\mathrm{B}$, enquanto que o conteúdo de silte no horizonte $\mathrm{B}$ varia de 0,2 a $2,3 \%$.

O relevo predominante é o suavemente ondulado a ondulado. Quando suavemente ondulado, as colinas apresentam declives suaves e formam vales em $\mathrm{V}$ abertos e, quando ondulados, as colinas ou morros são mais declivosos e os vales em $\mathrm{V}$ mais fechados. A altitude varia de 420 a 740 metros, sendo nas partes altas de 600 a 740 metros e nas baixas de 420 a 600 metros. A vegetação predominante original é a do tipo cerrado e o material original é arenito.

Os Neossolos Litólicos(RL), segundo Oliveira et al. (1999), são solos poucos desenvolvidos com espessura em torno de 35 $\mathrm{cm}$, constituído pelo horizonte A e a camada D. Granulometricamente, apresentam o conteúdo de argila em torno de 46,7\%, sendo a fração silte muito baixa, em torno de $2,1 \%$.

Estes solos ocupam os topos das elevações, distribuídos em pequenas manchas esparsas, sendo o relevo forte ondulado de 
topos arredondados, vertentes convexas, vales em V com declive em torno de $40 \%$ e a altitude em torno de 700 metros.

O clima predominante é o do tipo Cfa e o material original é o basalto, metáfiro e provavelmente diabásico (eruptivas básicas). A vegetação nativa predominante nestes solos é a floresta latifoliada tropical.

As áreas mapeadas como pertencentes à unidade de solo Latossolo Vermelho-Amarelos (LVA), segundo Oliveira et al. (1999) se caracterizam por serem solos profundos, de textura leve, bem drenados, de coloração vermelho amarelo, formados a partir de arenito, ácidos, de baixa fertilidade, de pequenas variações nas características, fazendo com que os vários sub-horizontes se apresentem pouco individualizados, com transição variando de gradual a difusa. A composição granulométrica deste solo apresenta o conteúdo de argila entre 15 a 30\%, nos horizontes A e B, sendo geralmente o teor de argila no horizonte $\mathrm{C}$ menor que no $\mathrm{B}$.

Estes solos localizam-se na região do alto planalto, onde formam manchas contínuas entrecortadas por solos de outras unidades.
Geralmente encontram-se nas superfícies dos espigões, que podem ser estreitas ou muito largas, apresentando uma topografia suavemente ondulada com pendentes de centenas de metros, ou completamente plana e, muito raramente, ondulada e mesmo assim de pendentes alongadas. A altitude varia de 500 a 1000 metros, estando a sua maior parte entre 600 a 900 metros.

A cobertura vegetal é variável, apresentando nas partes altas campo limpo, campo cerrado e cerrado, nas partes baixas é mais fina e de arbustos tortuosos, mas predominando campo cerrado e nas transições apresenta capoeira e cerradão quando a unidade vizinha é Nitossolos, contudo os arbustos do cerrado são mais eretos e vigorosos.

O clima predominante para esta unidade de solo é o Cfa, com índice pluviométrico variando de 1100 a $1700 \mathrm{~mm}$. O material de origem desses solos é constituído por arenito Botucatu, arenito Furnas e possivelmente sedimentos do terciário.

As características das três unidades de solo principais são apresentadas no Quadro 1.

Quadro 1. Características das três unidades de solo principais ocorrentes na bacia do Rio Capivara Botucatu (SP), segundo Oliveira et al. (1999).

\begin{tabular}{|c|c|c|c|}
\hline Características & LVA & RL & RQ \\
\hline Localização & Município de Botucatu & Município de Botucatu & Município de Botucatu \\
\hline Rocha & Grupo Bauru & & Formação Pirambóia \\
\hline Textura & Arenito & Arenito & Arenito \\
\hline Clima & Cfa & $\mathrm{Cfa}$ & $\mathrm{Cfa}$ \\
\hline Relevo & Suavemente ondulado & Forte ondulado & Suave ondulado \\
\hline Profundidade & Muito profundo & Baixa profundidade & Muito profundo \\
\hline Drenagem interna & Fortemente drenado & Moderadamente drenado & Excessivamente drenado \\
\hline Textura horizonte A & Média & Barro & Arenosa \\
\hline Textura horizonte B & Média & - & Arenosa \\
\hline Estrutura horizonte B & Maciça porosa & - & Maciça \\
\hline Retenção de água & Média a baixa & Baixa & Baixa a média \\
\hline Erodibilidade & Baixa & Muito susceptível & Baixa \\
\hline Fertilidade & Baixa a muito baixa & Alta & Muito baixa a baixa \\
\hline
\end{tabular}




\subsubsection{Bases cartográficas e pedológicas}

No presente estudo, os pontos de apoio planialtimétricos e de controle no processo de georreferenciamento da imagem digital do satélite, bem como as curvas de nível foram obtidos das cartas planialtimétricas do Instituto Brasileiro de Geografia e Estatística - IBGE, em escala $1: 50.000$, referentes aos municípios de Botucatu (SF-22-R-IV-3) e de Barra Bonita (SF-22-Z-IV-1), respectivamente, editadas em 1969 e 1978.

As unidades de solo ocorrentes na bacia do Rio Capivara - Botucatu (SP), foram obtidas do Mapa Pedológico do Estado de São Paulo, editado pela Oliveira et al. (1999).

\subsubsection{Dados orbitais}

Nesta pesquisa foram utilizados dados coletados pelo sensor Thematic Mapper (TM), instalado a bordo do satélite LANDSAT - 5, no formato digital, sob a forma de composição colorida das bandas TM3, TM4 e TM5, em escala $1: 50.000$, referentes à órbita 220 , ponto 76 , quadrante $\mathrm{A}$, passagem de $8 / 06 / 97$. As três diferentes bandas: TM - $3(630$ a $690 \mathrm{~nm})$, correspondente à região do vermelho; TM - 4 $(760$ a $900 \mathrm{~nm})$, correspondente ao infravermelho próximo e TM - 5 (1550 a 1750 $\mathrm{nm})$, correspondente ao infravermelho médio foram usadas para caracterização do uso do solo da bacia e das 10 microbacias.

\subsubsection{Equipamentos}

O processamento dos dados foi realizado num microcomputador Pentium III - $500 \mathrm{MHz}$, HD 13,0 Gb, $128 \mathrm{Mb}$ de memória RAM e impressora a jato de tinta HP Deskjet 692 C.

Para entrada das informações analógicas como a rede de drenagem, as curvas de nível, as unidades de solo e o limite das microbacias foi utilizado o Scanner Genius Vivid Pro II. Além destes, utilizou-se para a coleta e confirmação das coordenadas dos pontos de controle a campo e da ocupação do solo, um GPS de navegação GARMIN XL 45 GPS II.

\subsubsection{Aplicativos}

O "software" IDRISI - Sistema de Informações Geográficas foi usado no processamento das informações georreferenciadas e na classificação supervisionada do uso da terra, tendo como base a imagem de satélite. O "software" CARTALINX foi utilizado na digitalização das curvas de nível, rede de drenagem e unidades de solo, bem como no limite das microbacias.

\subsection{Método}

\subsubsection{Delimitação da área da bacia hidrográfica}

Segundo Argento \& Cruz (1996), a delimitação de uma bacia hidrográfica é dada pelas linhas divisoras de água que demarcam seu contorno. Estas linhas são definidas pela conformação das curvas de nível existentes nas cartas planialtimétricas e ligam os pontos mais elevados da região em torno da drenagem.

$\mathrm{O}$ contorno da área da bacia do Rio Capivara - Botucatu (SP) e das microbacias, objeto de estudo, foi realizado manualmente nas Cartas Planialtimétricas editadas pelo Instituto Brasileiro de Geografia e Estatística - IBGE em 1969 e 1978, respectivamente, folhas de Botucatu (SF-22-R-IV-3) e de Barra Bonita (SF-22-Z-IV-1), em escala 1:50.000, segundo os pontos mais elevados em torno da drenagem, tendo-se como base a definição de Rocha (1991) para bacia hidrográfica.

4.2.2. Obtenção da rede de drenagem da bacia e das 10 microbacias

$\mathrm{O}$ limite e a rede de drenagem da bacia e das 10 microbacias, objetos de estudo foram obtidos a partir do mapa da rede de drenagem 
da bacia do Rio Capivara - Botucatu (SP), segundo Araújo Júnior (1998).

Inicialmente foi feito a scanerização do mapa que continha a rede de drenagem referente à bacia do rio Capivara - Botucatu (SP) e as 10 microbacias hidrográficas. Desta forma, a importação analógica foi convertida para digital. Em seguida, fez-se a importação do formato .BMP gerado no processo de scanerização para o formato .IMG, pelo módulo File/Import. $\mathrm{O}$ próximo passo foi a georreferência do mapa digital para o sistema UTM (Universal Transverso de Mercator), utilizando-se de 4 pontos de controle localizados nos cantos da imagem (carta). O módulo utilizado neste processo foi $\mathrm{o}$ Reformat/Resample.

A digitalização do polígono máscara abrangendo a área total da bacia e das 10 microbacias foi efetuada pelo módulo $O n$ Screen Digitizing. Em seguida, fez-se a digitalização da rede de drenagem na tela do computador através do módulo de digitalização.

De posse da rede de drenagem, o próximo passo foi a rasterização das mesmas sobre o polígono da bacia e das microbacias. Utilizou-se para tanto, o módulo Reformat/Raster/Vector conversion/Lineras. A determinação da área da bacia e das microbacias foi realizada pelo módulo Analysis/Data Base QueryÄrea.

4.2.3. Obtenção do mapa de ocupação do solo pela classificação digital

Inicialmente, foi utilizado uma composição colorida com a combinação das bandas 3, 4 e 5, pois de acordo com Piroli (1999) esta apresenta uma boa discriminação visual dos alvos, possibilitando a identificação dos padrões de uso da terra de maneira lógica. Esta composição apresenta os corpos d'água em tons azulados, as florestas e outras formas de vegetações em tons esverdeados e os solos expostos em tons avermelhados.

A seguir, fez-se o georreferenciamento da composição colorida, utilizando-se para isso o módulo Reformat/Resample do SIG IDRISI, sendo os pontos de controle para o georreferenciamento obtidos nas cartas topográficas de Barra Bonita e de Botucatu, em escala $1: 50.000$. Após o georreferenciamento, foi feito o corte, extraindo-se a área da bacia do Rio Capivara, objeto de estudo. Posteriormente, foram demarcadas as áreas de treinamento sobre a imagem com o cursor e o mouse. Essas áreas foram demarcadas sobre grande número de locais, buscando-se abranger todas as variações de cada ocupação do solo.

Para a classificação supervisionada, as ocupações do solo foram identificadas $\mathrm{e}$ diferenciadas, umas das outras pelo seu padrão de resposta espectral, sendo as áreas de treinamento delimitadas por polígonos desenhados sobre cada uso da terra na imagem. Em seguida, foram indicadas os nomes para cada classe de uso da terra, associados aos seus respectivos identificadores.

Criou-se as assinaturas pelo módulo Makesig e realizou-se a classificação supervisionada propriamente dita pelo método de Máxima Verossimilhança, através do módulo Maxlike.

Elaborada a classificação supervisionada, foi feito o corte de cada microbacia, objeto de estudo, sendo a extração das áreas com os usos da terra efetuado pelo módulo Analysis/Data Base Query/Reclasss.

Para analisar a situação ocorrente em 1997, na identificação digital dos alvos em suas cores reais, utilizou-se das chaves de interpretação para imagens (Quadro 2), proposta por Rocha (1986).

Nesta classificação foram determinadas 6 classes de uso representativas com reflorestamento, solo exposto, uso agrícola, pastagens, capoeiras e matas. 
Quadro 2. Chave de interpretação das imagens orbitais, segundo Rocha (1986).

\begin{tabular}{ccc}
\hline Ocupação do solo & Cor & Textura \\
\hline Floresta primária & Verde escuro & Rugosa \\
Reflorestamento & Verde escuro & Lisa \\
Capoeiras & Verde claro & Rugosa \\
Campos de pastagens & Verde claro & Lisa \\
Agricultura anual & Amarelo claro & Lisa \\
Campos com solo exposto & Rosa claro & Lisa \\
Queimadas & Negro & Lisa \\
\hline
\end{tabular}

4.2.4. Avaliação das áreas do uso da terra de 1997

Após a elaboração do mapa de uso do solo, as áreas obtidas na imagem de satélite de 1997 pela classificação supervisionada e nas 10 microbacias hidrográficas, foram avaliadas e medidas com o auxílio do software SIG IDRISI.

Essas áreas das ocupações do solo da bacia do Rio Capivara - Botucatu (SP) foram determinadas, utilizando-se do comando "Area" do menu "Database Query", pertencente ao módulo "Analysis". Posteriormente foram elaborados os cartogramas demonstrativos da distribuição espacial de cada uso da terra ocorrentes na bacia do Rio Capivara.

\subsubsection{Análise da aptidão agrícola}

A análise da aptidão agrícola das 10 microbacias foi efetuada, considerando-se dentre os parâmetros físicos empregado para este tipo de estudo, os seguintes: a densidade de drenagem $(\mathrm{Dd})$, a declividade média $(\mathrm{H})$, os coeficientes de rugosidade (CR), de forma (Cf) e de circularidade $(\mathrm{Cc})$.

\subsubsection{Densidade de drenagem (Dd)}

A densidade de drenagem (Dd) é uma das variáveis relativa à característica do padrão de drenagem utilizada na análise da rede de drenagem de uma bacia hidrográfica. Esta é um parâmetro físico fundamental na análise comparativa da susceptibilidade entre microbacias, conforme Christofoletti (1974), pois relaciona o comprimento total da rede drenagem da microbacia $(\mathrm{Cr})$ em função da área (A) desta.

O comprimento total da rede drenagem da microbacia $(\mathrm{Cr})$ é obtido com o somatório das distâncias de todas as ravinas, canais e tributários existentes em uma microbacia. Quanto maior for o valor de $\mathrm{Cr}$, maior será o perigo de erosão.

Os comprimentos das redes de drenagem foram determinados, utilizando-se do comando "Perim" do menu "Database Query", pertencente ao módulo "Analysis", sendo posteriormente determinada a densidade de drenagem de cada microbacia, conforme Christofoletti (1974).

\subsubsection{Declividade média $(\mathrm{H})$}

A declividade média do terreno é um parâmetro fundamental para se estudar os picos de enchentes e a infiltração de água no solo. Ela determina o escoamento da águas das chuvas e, quanto maior o declive, maior será o escoamento da água pela superfície e, consequentemente, maior será os riscos de erosão (Mota, 1981).

A declividade média $(\mathrm{H})$ das 10 microbacias hidrográficas foi calculada pela expressão proposta por Horton (1914): $\mathrm{H}=100$ . D . L/A, onde: $H=$ Declividade média da bacia em \%; D = Eqüidistância vertical das curvas de nível em $\mathrm{Km}$; L = Comprimento total 
das curvas de nível da bacia em Km e A = Área total da bacia em $\mathrm{Km}^{2}$.

Os comprimentos das curvas de nível foram determinados, utilizando-se do comando "Perim" do menu "Database Query", pertencente ao módulo "Analysis", sendo posteriormente determinada a declividade média de cada microbacia, conforme Horton (1914).

\subsubsection{Coeficiente de forma (Cf)}

O coeficiente de forma foi determinado pela relação entre a área englobada simultaneamente pela figura geométrica considerada e a microbacia, com a área total que pode ser a da microbacia e/ou da figura geométrica, conforme Ler \& Sales, citados por Souza (1977), ou seja: $\mathrm{Cf}=1-\{(\mathrm{A} \cap \mathrm{L}) / \mathrm{A}\}$, onde: $\mathrm{A}=$ Área da microbacia em ha $\mathrm{e} \mathrm{L}=$ Área da figura geométrica envolvente com forma mais próxima possível da forma da microbacia em ha.

As áreas total e da figura geométrica considerada foram determinadas, utilizando-se do comando "Area" do menu "Database Query", pertencente ao módulo "Analysis", sendo posteriormente determinado o coeficiente de forma de cada microbacia, conforme Ler \& Sales, citados por Souza (1977).

\subsubsection{Coeficiente de circularidade $(\mathrm{Cc})$}

O coeficiente de circularidade foi determinado pela relação entre a área da microbacia em hectares (A) e a área do círculo de perímetro igual ao da microbacia considerada em hectares (Ac), segundo Miller (1953), citado por Christofoletti (1974): $\mathrm{Cc}=\mathrm{A}$ / Ac.

Os comprimentos dos perímetros e áreas foram determinados, utilizando-se do comando "Perim" e "Area", respectivamente, do menu "Database Query", pertencente ao módulo "Analysis", pertencente ao módulo "Analysis", sendo posteriormente calculado o coeficiente de circularidade de cada microbacia, conforme Miller apud Christofoletti (1974).

\subsubsection{Coeficiente de rugosidade (CR)}

O coeficiente de rugosidade (CR), por ser um parâmetro que direciona o uso potencial das terras rurais, quanto às suas características para atividades de agricultura, pecuária, silvicultura com reflorestamento ou para preservação permanente, será usado para definir as 4 classes de uso da terra das 10 microbacias hidrográficas da bacia do rio Capivara Botucatu (SP), que são: A (menor valor de CR) - terras apropriadas à agricultura; $\mathrm{B}$ - terras apropriadas à pecuária; $\mathrm{C}$ - terras apropriadas à pecuária e reflorestamento e $\mathrm{D}$ (maior valor de $\mathrm{CR})$ - terras apropriadas à florestas e reflorestamento, segundo Rocha (1991), que é definido também pelo mesmo autor, conforme expressão: $\mathrm{CR}=\mathrm{Dd}$. $\mathrm{H}$, onde: $\mathrm{CR}=$ Coeficiente de rugosidade; $\mathrm{Dd}=$ Densidade de drenagem e $\mathrm{H}=$ Declividade média.

\subsubsection{Classificação das microbacias}

As microbacias foram classificadas segundo metodologia preconizada por Rocha (1989) em 4 classes para o RN, quais sejam: A - Solos apropriados para agricultura (menor valor de $\mathrm{RN}$ ); $\mathrm{B}$ - Solos apropriados para pastagens; $\mathrm{C}-$ Solos apropriados para pastagens e reflorestamento e D - Solos apropriados para reflorestamento (maior valor de $\mathrm{RN}$ ).

As classes A, B, C e D para caracterização do uso potencial da terra de cada bacia foram obtidos através do cálculo da amplitude, que é a diferença entre o maior e o menor valor de $\mathrm{RN}$ encontrado para as bacias de terceira ordem de ramificação e o intervalo de domínio, que é a relação entre a amplitude dividido por 4, que é o número de classes preconizadas pelo método de Sicco Smith apud Rocha (1989). 


\subsubsection{Estudo dos conflitos}

\subsubsection{1. Áreas de conflito}

Para se determinar as áreas de conflito de uso da terra numa microbacia hidrográfica , levou se em consideração que os conflitos podem ocorrer de duas maneiras: 1 - quando o tipo de uso da terra contraria o destino da mesma recomendado a partir do coeficiente de rugosidade; ou 2 - quando o uso atual da terra, mesmo coincidente com o indicado pelo coeficiente de rugosidade, subestime o potencial da terra, com baixa produtividade por técnicas inadequadas, ineficientes ou condenáveis.

\subsubsection{Uso da terra e reflorestamento}

As áreas planas, nas quais o coeficiente de rugosidade $(\mathrm{CR})$ indicou destinação para agricultura (Classe $\mathrm{A}$ ), mas que não foram empregadas para esse meio produtivo, ou embora fossem utilizadas, porém apresentaram uma declividade superior a $10 \%$, exigindo tratos conservacionistas foram consideradas como áreas de conflito. Essas áreas com até $15 \%$ de declividade média foram indicadas neste estudo para o uso com pecuária leiteira, atividade rural mais expressiva da região, e porque oferecem condições de uso com máquinas e implementos agrícolas.

Para as microbacias com essas características foi ainda indicado o reflorestamento mínimo de $25 \%$, necessário para protegê-las contra a erosão e os efeitos das secas e das enchentes, conforme sugere Rocha (1986). E quando a declividade era maior que $15 \%$, indicou-se o reflorestamento como forma de cobertura vegetal até atingir-se um mínimo de $50 \%$, de acordo com recomendações do mesmo autor, para esses casos.

As bacias, as quais o coeficiente de rugosidade indicou exploração com pastagem (Classe B) e por pastagem/reflorestamento (Classe C) que apresentavam declividade média superior a $15 \%$ sugere-se reflorestá-las até atingir-se 50\% de cobertura florestal, conforme Rocha (1991).

Posteriormente, foram determinadas as porcentagem de ocorrências destas em relação à área total de cada bacia.

\subsubsection{A reflorestar}

A área mínima de cobertura florestal que uma bacia deve ter é de $25 \%$, quando esta apresenta-se com declividade média até $15 \%$. Neste trabalho, as microbacias que apresentarem-se com declividade superior a $15 \%$, o reflorestamento mínimo indicado foi da ordem de $50 \%$. Nesses casos, a porcentagem da área a ser reflorestada em cada bacia foi igual à diferença, respectivamente, entre a porcentagem de reflorestamento mínimo indicado $(50 \%)$ e de florestas existentes. A área a ser reflorestada foi determinada pelo produto da porcentagem a ser reflorestada e área da bacia dividido por 100.

\subsubsection{Excesso ou disponibilidade agrícola}

As áreas em que o coeficiente de rugosidade indicou terras propícias para agricultura (Classe A), o excesso $(+)$ ou a disponibilidade (-) em agricultura foram determinados pela diferença entre a área total da bacia e a somatória das ocupações do solo: matas naturais primárias e capoeiras; reflorestamento, pastagens naturais e artificiais; áreas construídas e urbanizadas e açudes, barragens e outros. A porcentagem de excesso ou disponibilidade foi a relação entre esse valor determinado e a área total da bacia multiplicado por 100 .

Nas áreas indicadas para pastagem segundo o coeficiente de rugosidade (Classe B), para pastagem e/ou reflorestamento (Classe C) e reflorestamento (Classe D), o excesso ou disponibilidade em agricultura foi igual à área ocupada por culturas agrícolas. 
4.2.6.5. Área a ser trabalhada para o manejo correto da microbacia

A área a ser trabalhada para o manejo correto da bacia nas áreas planas, onde o coeficiente de rugosidade indicou terras

propícias para agricultura (Classe A) foi a somatória das áreas de conflitos, a reflorestar e disponibilidade em agricultura. As áreas de Classes A, B e D foram determinadas pela soma das áreas a reflorestar e disponíveis para agricultura, conforme Rocha (1991). A porcentagem foi a relação entre a área a ser trabalhada para o manejo correto da bacia pela área da bacia multiplicado por 100 .

\subsubsection{Degradação das microbacias}

A área degradada em cada microbacia foi obtida pela soma das áreas de conflito e a reflorestar e A porcentagem de deterioração da microbacia foi determinada pela relação entre a área deteriorada e a área total da bacia multiplicado por 100 .

O grau de deterioração da bacia hidrográfica do rio Capivara - Botucatu (SP) foi definido pela média aritmética das porcentagens de deterioração das 10 microbacias.

\section{RESULTADOS E DISCUSSÃO}

\subsection{Uso da terra nas 10 microbacias}

O Quadro 3, que apresentam os usos da terra das 10 microbacias estudadas mostram que grande parte da superfície destas estão ocupadas por vegetação em forma de florestas. Percebe-se que em média mais de $30 \%$ das superfícies das microbacias estão ocupadas com vegetação arbórea do tipo mata e capoeira. Este é um parâmetro muito importante, pois de acordo com Rocha (1990), as matas são fundamentais no controle de erosão e de enchentes, pois quando estão situadas em locais adequados são fundamentais na recarga do lençol freático.

A terceira cobertura vegetal mais importante presente nas microbacias foram as pastagens, que mesmo sendo má conduzida, a pecuária bovina de leite tem uma certa predominância na região.

As matas, capoeiras e pastagens representaram mais de $50 \%$ da área abrangida pelas microbacias, refletindo assim a predominância de solos de baixa fertilidade, conforme Barros et al. (1990) e Campos (1993)

Quadro 3. Ocupação do solo das 10 microbacias hidrográficas, em 1997.

\begin{tabular}{ccccccc}
\hline \multicolumn{7}{c}{ Ocupação do solo (\%) } \\
\hline & Uso agrícola & Reflorestamento & Pastagens & $\begin{array}{c}\text { Solo } \\
\text { exposto }\end{array}$ & Capoeira & Mata \\
1 & 26,84 & 19,36 & 26,800 & 1,21 & 21,54 & 4,25 \\
2 & 21,65 & 27,28 & 19,75 & 0,00 & 24,92 & 6,40 \\
3 & 8,94 & 76,03 & 0,73 & 0,00 & 9,99 & 4,31 \\
4 & 36,60 & 16,09 & 25,74 & 1,75 & 12,49 & 7,33 \\
5 & 38,84 & 3,02 & 24,51 & 0,98 & 19,62 & 13,03 \\
6 & 13,30 & 2,06 & 54,12 & 0,00 & 12,27 & 18,25 \\
7 & 49,92 & 1,37 & 18,05 & 0,40 & 9,18 & 21,08 \\
8 & 46,42 & 2,42 & 16,19 & 0,27 & 12,64 & 22,06 \\
9 & 46,50 & 1,17 & 24,84 & 0,13 & 13,16 & 14,20 \\
10 & 13,05 & 11,21 & 17,09 & 0,00 & 49,90 & 8,75 \\
Média & 30,21 & 16,00 & 22,78 & 0,47 & 18,57 & 11,97 \\
\hline
\end{tabular}




\subsection{Aptidão agrícola}

5.2.1. Densidade de drenagem (Dd)

O Quadro 4 mostra que as microbacias 5, 9 e 10 apresentam densidade de drenagem mais elevada, merecendo maiores cuidados quanto ao controle de erosão. Provavelmente, isto está ocorrendo em função de solos poucos permeáveis (RQ) ocorrentes nestas microbacias, terrenos com declividades médias mais acentuados, ausência de vegetação e rochas poucos resistentes.

Quadro 4. Área, comprimento total de rios e densidade de drenagem das 10 microbacias hidrográficas.

\begin{tabular}{ccccccc}
\hline Microbacia & $\begin{array}{c}\dot{A} \\
\text { (ha) }\end{array}$ & $\begin{array}{c}\mathrm{Dd} \\
(\mathrm{Km} / \mathrm{ha})\end{array}$ & $\begin{array}{c}\mathrm{H} \\
(\%)\end{array}$ & $\mathrm{CR}$ & $\mathrm{Cf}$ & $\mathrm{Cc}$ \\
\hline 1 & 4007,19 & 0,01383 & 8,27 & 0,58 & 0,58 & 0,4823 \\
2 & 608,01 & 0,01316 & 10,43 & 0,61 & 0,61 & 0,4852 \\
3 & 836,01 & 0,00538 & 9,77 & 0,58 & 0,58 & 0,6346 \\
4 & 1107,07 & 0,01039 & 10,34 & 0,58 & 0,58 & 0,7233 \\
5 & 3135,22 & 0,02310 & 12,77 & 0,59 & 0,59 & 0,5917 \\
6 & 956,07 & 0,01912 & 11,08 & 0,58 & 0,58 & 0,6528 \\
7 & 966,51 & 0,01871 & 14,50 & 0,59 & 0,59 & 0,5546 \\
8 & 752,50 & 0,00727 & 18,37 & 0,58 & 0,58 & 0,6324 \\
9 & 2051,13 & 0,02610 & 19,14 & 0,61 & 0,61 & 0,4467 \\
10 & 1656,00 & 0,02686 & 17,91 & 0,56 & 0,56 & 0,4997 \\
Média & 1607,57 & 0,01639 & 13,26 & & & 0,5703 \\
\hline
\end{tabular}

\subsubsection{Declividade média $(\mathrm{H})$}

A média das declividades média das 10 microbacias, estudadas na bacia do rio Capivara - Botucatu (SP) foi de 13,26\% (Quadro 4). Segundo Chiarini \& Donzeli (1973), o relevo é classificado como forte ondulado, sendo impróprio para o cultivo de culturas anuais e indicado para a o uso de pastagens em eventual rotação com culturas anuais e podendo ser exploradas com culturas permanentes que protegem o solo (café, laranja, cana-de-açúcar, leguminosas como forma de adubação verde, etc.), pois são terras sujeitas à erosão e a prática da conservação do solo é imprescindível, segundo Lepsch et al. (1991). Portanto, atividades agrícolas em áreas impróprias e de forma inadequada devem ser consideradas como uma prática de risco, pois se as práticas conservacionistas não forem utilizadas nestes casos, as bacias sofrerão grandes perdas de solos por erosão.

Examinando os dados referentes ao Quadro 4 verifica-se que as declividades médias para as bacias $1(8,27 \%) ; 2(10,43 \%) ; 3$ $(9,77 \%) ; 4(10,34 \%)$ e $6(11,08 \%)$, permitem classificá-las de acordo com o coeficiente de rugosidade para utilização de agricultura e de urbanização. Esses valores encontrados para a declividade são apenas médios, uma vez, que podemos encontrar áreas com declividade mais acidentada (mais de 20\% de declive) que preconizam o uso do solo para pecuária, florestas e reflorestamentos.

As declividades média para as bacias 5 (12,77\%); 7 (14,50\%); 8 (18,37\%); 9 (19,14\%) e $10(17,91 \%)$, permitem classificá-las de acordo com o coeficiente de rugosidade para utilização de agricultura e de urbanização.

A declividade média das microbacias 1 , 2, 3, 4 e 6 permitiu classificá-las como relevo plano ondulado, conforme critérios 
preconizados por Chiarini \& Donzeli, 1973) e que segundo Lepsch et al. (1991) são terras indicadas para cultivo com culturas anuais, enquanto que as microbacias $5,7,8,9$ e 10) foram classificadas como relevo forte ondulado e que segundo Lepsch et al. (1991), são terras com declives acentuados, inúteis para plantio com culturas anuais, sendo mais propícias para pastagens, em eventual rotação com culturas anuais.

\subsubsection{Coeficiente de forma (Cf)}

As microbacias $1,3,4,6,7,8$ e 10 se aproximam mais da forma retangular, enquanto que as microbacias 2, 5 e 9 mais da forma triangular. Sabe-se que, de acordo com Souza (1977), as microbacias de formatos circulares, ovais ou quadradas apresentam um maior perigo de enchentes, quando comparadas com as de formato triangular ou retangular, que têm maiores possibilidades de chuvas intensas ocorrerem simultaneamente em toda sua extensão, concentrando grande volume de água ao tributário principal. Porém, sabe-se que o perigo de enchente depende também de outros parâmetros, como a permeabilidade dos solos e a vegetação reinante.

\subsubsection{Coeficiente de Circularidade (Cc)}

O coeficiente de circularidade médio para as microbacias estudadas, da ordem de 0,5703 (Quadro 4), permitem inferir que estas apresentam perigo de enchentes mediano, pois segundo Miller (1953), citado por Cristofoletti (1974), o coeficiente de circularidade mostra que quanto mais próximo da unidade estiver o seu valor, mais a microbacia estará próxima do formato circular, e quanto maior for esse valor, maior será o perigo de enchentes.

No entanto, os riscos de erosão e de enchentes nas microbacias deve ser analisado mais profundamente em função de outros parâmetros, pois a vegetação e a permeabilidade do solo são fundamentais nesse controle.

\subsubsection{Coeficiente de Rugosidade (RN)}

O coeficiente de rugosidade é um parâmetro que direciona o uso potencial da terra com relação às suas aptidões para agricultura, pecuária ou reflorestamento (Rocha, 1991). Ele mostra também a realidade de uma bacia, oferecendo uma contribuição simples, rápida e precisa ao planejamento, para melhor e mais justa exploração econômica, em função da vocação de suas terras (Pereira Filho, 1986). Esse autor coloca também que existe uma alta correlação entre o coeficiente de rugosidade e a capacidade de uso da terra, ao nível de $0,5 \%$ de erro.

A análise detalhada do coeficiente de rugosidade (Quadro 4) mostra que as microbacias estudadas $1,2,3,4$, e 8 têm vocação para uso com agricultura e urbanização (Classe A), enquanto que as microbacias 6 e 7 têm vocação para uso com pecuária (Classe $\mathrm{B}$ ); a microbacia 5 tem vocação para uso com pecuária e reflorestamento (Classe $\mathrm{C}$ ) e as microbacias 9 e 10 têm vocação para uso com florestas e reflorestamento (Classe D), conforme metodologia preconizada por Rocha (1991).

O coeficiente de rugosidade médio das microbacias indica que a bacia do Rio Capivara - Botucatu (SP) apresenta vocação principal para uso com pecuária (Classe B), sendo o seu relevo classificado como forte ondulado (Chiarini \& Donzeli, 1973) e as terras inviáveis para o cultivo com culturas anuais, sendo mais indicadas para pastagens, com eventual rotação com culturas anuais; o que concorda com os dados regionais, pois mesmo sendo mal conduzida, a pecuária bovina leiteira tem uma certa predominância regional.

O uso da terra, a partir do coeficiente de rugosidade, parâmetro ambiental utilizado por muitos pesquisadores, como Rocha (1991), Mello Filho \& Rocha (1992) e outros, na classificação do uso das terras apropriadas para exploração de agricultura e urbanização (Classe $\mathrm{A})$; pecuária (Classe $\mathrm{B}$ ); pecuária $\mathrm{e}$ reflorestamento (Classe C) e reflorestamento (Classe D), para o estudo do manejo integrado das bacias hidrográficas, indica propensão não exclusivista. Pois, ao avaliar-se particularmente 
cada bacia, verifica-se que estas apresentam relevo muito variado, indicando o uso diferente ao definido para a própria bacia. Isto pode ser constatado ao analisar-se as particularidades de cada local no interior da bacia, conforme determinado pelo coeficiente de rugosidade, principalmente onde o relevo é ondulado e fortemente ondulado.

\subsection{Unidades de solo}

Analisando-se o Quadro 5 que apresenta as áreas totais em hectares e a porcentagens das unidades de solo ocorrentes nas 10 microbacias hidrográficas da bacia do Rio Capivara Botucatu (SP), segundo Oliveira et al. (1999), verificamos que as 10 microbacias apresentaram, 97,84\% com as unidades de solo RQ, LVA, e RL, respectivamente, na ordem de $50,45 \% ; 21,02 \%$ e $26,37 \%$, ficando os outros $2,16 \%$ restantes para as classes de solo, respectivamente, GX $(2,12 \%)$ e LR $(0,04 \%)$. Contudo, as bacias 1, 2, 3, 4 e 5, apresentaram em média, $81,92 \%$ da unidade de solo RQ, respectivamente, da ordem de $100 \% ; 100 \%$; $97,97 \% ; 59,46 \%$ e $52,16 \%$. Segundo a Oliveira et al. (1999), a unidade de solo RQ são solos profundos, textura muito leve, drenagem acentuada, fertilidade baixa, ácidos, muito susceptíveis à erosão, relevo suavemente ondulado, enquanto que a unidade de solo LR são solos que apresentam textura média, drenagem moderada, profundidade média, resistência média à erosão, alta fertilidade, relevo suave.

Quadro 5. Unidades de solo ocorrentes nas 10 microbacias hidrográficas, segundo a Oliveira et al. (1999).

\begin{tabular}{cccccc}
\hline \multicolumn{7}{c}{ Unidades de solo (\%) } \\
\hline Microbacia & RQ & LVA & LV & RL & GX \\
1 & 100,00 & - & - & - & - \\
2 & 100,00 & - & - & - & - \\
3 & 97,97 & - & - & - & 0,03 \\
4 & 59,46 & 22,66 & - & - & 7,88 \\
5 & 52,16 & 24,89 & - & 2,95 & - \\
6 & - & 95,79 & - & 0,21 & - \\
7 & - & 95,15 & - & 0,85 & - \\
8 & - & 54,84 & - & 0,16 & - \\
9 & - & 4,89 & - & 8,95 & 0,16 \\
10 & 23,11 & - & 0,33 & 6,56 & - \\
Total & 50,45 & 21,02 & 0,04 & 6,37 & 0,12 \\
\hline
\end{tabular}

Os solos RL são solos profundos com baixa profundidade, de textura argilosa e drenagem moderada, de relevo forte ondulado, originados a partir de basaltitos, de alta fertilidade.

A bacia 10, constituída de aproximadamente de $3 / 4$ de solos RL e $1 / 4$ com o solo RQ.

As bacias $6,7,8$ e 9 constituídas totalmente de solos de média fertilidade, apresentaram em média com $62,67 \%$ de solos
LVA, respectivamente, 95,79\%; 95,15\%; $54,84 \%$ e $4,89 \%$ e em média com $35,79 \%$ de solos com alta fertilidade (RL), respectivamente, 4,21\%; 4,85\%; 45,16\% e $88,95 \%$. Os solos LVA apresentam topografia suavemente ondulada, textura leve, bem drenados, profundos, baixa resistência à erosão, fertilidade baixa a muito baixa. 
4.4. Determinação dos conflitos de uso da terra e complementação florestal

A ocorrência dos conflitos pode ser observada pelo uso da terra em 1997 contrário à tendência definida a partir do coeficiente de rugosidade nas 10 microbacias estudadas na bacia hidrográfica do rio Capivara - Botucatu (SP). Por outro lado, o Quadro 6, mostra os resultados obtidos para a área a ser reflorestada, atende às exigências legais pelo Código Florestal, lei n. ${ }^{\circ} 4.771$ de 15/09/65, alterada pelas leis 7.803 de 18/07/8 9 e 7.895 de $13 / 11 / 89$, bem como, as recomendações técnicas em função da declividade média de cada bacia, com a finalidade de protegê-las contra a erosão e os efeitos das enchentes (Rocha, 1991).

De maneira geral, a pecuária na região é desenvolvida de forma extensiva com pastagens de baixa qualidade $\mathrm{e}$ os produtores não costumam efetuar correções do $\mathrm{pH}$ (calagem) e adubação de manutenção nas pastagens para melhorar a qualidade desse alimento. Como a conservação do solo é uma prática agronômica pouco utilizada pelos pecuaristas, consequentemente os solos que por natureza são pobres, acabam sofrendo com a ação das intempéries, acarretando em assoreamentos do rio Capivara, bem como a diminuição da capacidade de suporte da vegetação para o gado, tendo como conseqüência a queda na produção leiteira. A degradação média ambiental da bacia do rio Capivara foi de $44,34 \%$, levando a crer que a área de pecuária como conflito é o indicador direto desse alto grau de deterioração, grau esse muito acima do limite aceitável, que é de $10 \%$. Esses dados evidenciam cada vez mais a diminuição da qualidade do meio ambiente por parte do ser humano. $\mathrm{O}$ uso inadequado das terras tem causado permanentes prejuízos para o solo e para a vegetação, podendo estar contribuindo com o baixo nível sócio-econômico dos proprietários rurais da região de Botucatu, pois as práticas agrícolas adotadas pelos pecuaristas são ineficientes economicamente $\mathrm{e}$ depredatórias ambientalmente.

$\mathrm{O}$ uso inadequado das terras, as declividades médias acentuadas nas bacias e o desmatamento desordenado, que outrora foi submetido essas áreas, sugerem que todas as microbacias precisam ser repovoadas de 3,92\% a $41,25 \%$ com reflorestamento. As florestas remanescentes vem diminuindo ao longo dos anos, como podemos observar pelos valores de 1989, que eram em média de 11,97\%.

Quadro 6. Determinação dos conflitos, uso do solo, complementação florestal e deterioração das 10 microbacias hidrográficas.

\begin{tabular}{|c|c|c|c|c|c|c|c|}
\hline \multirow[t]{2}{*}{ Microbacia } & \multicolumn{2}{|c|}{ Conflitos } & \multirow{2}{*}{$\begin{array}{c}\text { Florestas } \\
\qquad \%\end{array}$} & \multirow{2}{*}{$\begin{array}{c}\text { A } \\
\text { Reflores- } \\
\text { tar }\end{array}$} & \multirow{2}{*}{$\begin{array}{c}\text { Excesso }(+) \text { ou } \\
\text { disponibilidade } \\
(-) \text { em } \\
\text { agricultura } \\
\%\end{array}$} & \multirow{2}{*}{$\begin{array}{c}\text { Área a ser } \\
\text { trabalhada para } \\
\text { manejo correto } \\
\text { da bacia } \\
\%\end{array}$} & \multirow{2}{*}{$\begin{array}{c}\text { Área de } \\
\begin{array}{c}\text { Deterioração } \\
\text { por } \\
\text { microbacia }\end{array} \\
\%\end{array}$} \\
\hline & CR & $\%$ & & & & & \\
\hline 1 & $\mathrm{~A}$ & - & 4,25 & 20,75 & 48,16 & 68,91 & 20,75 \\
\hline 2 & A & 21,65 & 6,40 & 18,60 & 53,35 & 93,60 & 40,25 \\
\hline 3 & A & - & 4,31 & 20,69 & 66,06 & 86,75 & 20,69 \\
\hline 4 & A & 36,60 & 7,37 & 17,67 & 38,44 & 92,67 & 54,23 \\
\hline 5 & $\mathrm{C}$ & 57,04 & 13,03 & 11,97 & 57,04 & 69,01 & 69,01 \\
\hline 6 & B & 13,30 & 18,25 & 6,75 & 13,30 & 20,05 & 20,05 \\
\hline 7 & B & 49,92 & 21,08 & 3,92 & 49,92 & 53,84 & 53,84 \\
\hline 8 & A & 46,42 & 22,06 & 27,94 & 3,58 & 77,94 & 74,36 \\
\hline 9 & $\mathrm{D}$ & 71,34 & 14,20 & 35,80 & 46,50 & 82,30 & 100,00 \\
\hline 10 & $\mathrm{D}$ & 30,14 & 8,75 & 41,25 & 13,05 & 54,30 & 71,39 \\
\hline Média & B & 31,31 & 11,97 & 13,03 & 31,31 & 44,34 & 44,34 \\
\hline
\end{tabular}


As altas declividades médias presentes em todas as 10 microbacias (Quadro 6) e o desmatamento pelo qual as áreas das microbacia foram submetidas, principalmente para as microbacias 6 e 7 , que apresentam pouca cobertura florestal nativa, respectivamente, $6,75 \%$ e $3,92 \%$ mostram que todas as microbacias necessitam de uma complementação florestal com reflorestamentos, pois segundo Cardoso (1988), a cobertura por reflorestamento é eficiente na proteção da rede de drenagem em regiões com processos erosivos.

O Quadro 6 também mostra que todas as microbacias necessitam ser reflorestadas, em média $13,03 \%$, para atingir a recomendação técnica de $50 \%$ de cobertura florestal como meta para a proteção e manejo da bacia de forma mais racional e adequada, procurando-se desta forma protegê-la contra a erosão, e consequentemente melhorando as condições ambientais.

\section{CONCLUSÕES}

De acordo com a metodologia utilizada e com os resultados obtidos para o estudo proposto foram possíveis concluir que as imagens do Sensor TM do LANDSAT 5, permitiram o mapeamento do uso da terra da bacia de maneira rápida, além de fornecer um excelente banco de dados para futuros planejamentos nessa área; o SIG - IDRISI permitiu constatar através de seus diferentes módulos para georreferenciamento, classificação digital do uso da terra e modelo matemático, as áreas de uso da terra com rapidez; a bacia vem sendo preservada em termos de conservação do solo, pois apresentase coberta com mais de $40 \%$ com matas, capoeiras e povoamentos com Eucaliptos; as áreas com uso agrícola forma os principais componentes da paisagem da bacia, ocupando $34,04 \%$ da bacia; o alto índice de ocupação do solo por povoamentos com matas, pastagens e capoeiras refletem a predominância de solos arenosos com baixa fertilidade; as classes de uso da terra, uso agrícola e pastagem, predominaram em $3 / 5$ da bacia, mostrando assim o domínio da agropecuária; a média das declividade média permitiu classificar o relevo da bacia do Rio Capivara como relevo forte ondulado, ou seja, terras impróprias para culturas anuais, indicadas para pastagens; os coeficientes de forma e circularidade mostraram que o formato das microbacias apresentam baixo perigo de enchentes. E o coeficiente de rugosidade permitiu classificar as microbacias $1,2,3,4$ e 8 com vocação para agricultura e urbanização; as 6 e 7 para pecuária; a 5 para pecuária e reflorestamento e as 9 e 10 para floresta e reflorestamento.

\section{AGRADECIMENTOS}

Os autores agradecem à FAPESP pela concessão da bolsa de doutorado, sem a qual não seria possível a realização deste trabalho.

\section{REFERÊNCIAS BIBLIOGRÁFICAS}

\author{
ARAÚJO JÚNIOR, A . A. de. Capacidade de \\ Uso das Terras do Rio Capivara (SP). 1998. \\ 94 f. Dissertação (Mestrado em Agronomia) - \\ Faculdade de Ciências Agronômicas, \\ Universidade Estadual Paulista, Botucatu, 1998. \\ ARGENTO, M.S.F.; CRUZ, C.B.M. \\ Mapeamento geomorfológico. In: CUNHA, \\ S.B.; GUERRA, A.J.T. (Org.) Geomorfologia: \\ exercícios, técnicas e aplicações. Rio de \\ Janeiro: Bertrand Brasil, 1996. Cap. 9, p. 264- \\ 282. \\ BARROS, Z. X. de; PIEDADE, G. C. R.; \\ CURI, P. R. Variáveis de ocupação do solo e \\ análise multivariada. Revista de Geografia, \\ São Paulo, n. 8/9, 1990. \\ CAMPOS, S. Fotointerpretação da ocupação \\ do solo e suas influências sobre a rede de \\ drenagem da bacia do Rio Capivara - \\ Botucatu (SP), no período de 1962 a 1977.
}


1993. 164 f. Tese (Doutorado em Agronomia) Faculdade de Ciências Agronômicas, Universidade Estadual Paulista, Botucatu, 1993. CARDOSO, L. G. Comportamento das redes de drenagem em solos com cana-de-açúcar e com eucalipto. 1988. 139 f. Tese (Doutorado em Agronomia) - Faculdade de Ciências Agronômicas, Universidade Estadual Paulista, Botucatu, 1988.

CHIARINI, J. J.; DONZELLI, P. L. Levantamento por fotointerpretação das classes de capacidade de uso das terras do Estado de São Paulo. Boletim Técnico do Instituto Agronômico, Campinas, n. 3, p.1-29, 1973. CHRISTOFOLETTI, A. Geomorfologia. São Paulo: Edgard Blücher, 1974.149 p. HORTON, R.E. Derivation of runoff from rainfall data. Discussion. Transactions of the ASAE, St. Joseph, v. 77, n. 2, p. 369-375, 1914.

LEPSCH, J.F. et al. Manual para levantamento utilitário do meio físico e classificação de terras no sistema de capacidade de uso. Campinas: Sociedade Brasileira de Ciencia do Solo, 1991. 175 p. MARTINS, D. Clima na região de BotucatuSP. In: ENCONTRO DE ESTUDOS SOBRE A AGROPECUÁRIA DE BOTUCATU, 1989, Botucatu. Anais... Botucatu: Universidade Estadual Paulista, 1989. p. 8.

MELLO FILHO, J. A.; ROCHA, J. S. M. da. Diagnóstico físico-conservacionista da subbacia hidrográfica do rio Sesmaria, em Resende- RJ. In: CONGRESSO BRASILEIRO DE ENGENHARIA AGRÍCOLA, 21., 1992. Santa Maria, RS. Anais... Santa Maria: Sociedade Brasileira de Engenharia Agrícola/Universidade Federal de Santa Maria,1992. p. 2178-2191.
MOTA, S. Planejamento urbano e preservação ambiental. Fortaleza: Edições Universidade Federal do Ceará, 1981. 242 p. OLIVEIRA, J. B. de et al. Mapa pedológico do Estado de São Paulo. Campinas: Empresa Brasileira de Pesquisa Agropecuária, 1999. 64 p. PEREIRA FILHO, W. Capacidade de uso da terra em função do coeficiente de rugosidade. 1986. 48 f. Dissertação (Mestrado em Agronomia) Universidade Federal de Santa Maria, Santa Maria, RS, 1986.

PIROLI, E. L. Sistema de informação geográfica e imagens de satélite para análise do uso da terra na microbacia do Arroio do Meio - Santa Maria, RS. 1999. 97 f.

Dissertação (Mestrado em Agronomia), Universidade Federal de Santa Maria, Santa Maria, RS, 1999.

ROCHA, J.S.M. da. Manual de interpretação de aerofotogramas. Santa Maria: Universidade Federal de Santa Maria, 1986. 58 p. (Fascículo 11)

ROCHA, J. S. M. da. Manejo integrado de bacias hidrográficas. 2. ed. Santa Maria: Universidade Federal de Santa Maria, 1989. $195 \mathrm{p}$.

ROCHA, J.S.M. da. Manual de manejo integrado de bacias hidrográficas. 2 . ed. Santa Maria: Universidade Federal de Santa Maria, 1991. 181 p.

SOUZA, E.B. Fotointerpretação da rede de drenagem na diferenciação de unidades de mapeamento de solos ocorrentes na depressão central do Rio Grande do Sul. 1977. 99 f. Tese (Doutorado em Agronomia) Universidade Federal de Santa Maria, Santa Maria, RS, 1077. 